\title{
Reports of the Death of Expertise May Be Exaggerated: Limits on Knowledge Resistance in Health and Medicine
}

\author{
Henri C. Santos, Michelle N. Meyer, \& Christopher F. Chabris* \\ Geisinger Health System, Danville, Pennsylvania, U.S.A. \\ To appear in: J. Stromback, Å. Wikforss, K. Glüer, T. Lindholm, \& H. Oscarsson (Eds.). \\ Knowledge Resistance in High-Choice Information Environments. London: Routledge. \\ *Address correspondence to: chabris@gmail.com
}

\begin{abstract}
During the past decade the idea that expertise is dead, or at best moribund, has become commonplace. Knowledge resistance appears to be growing more politicized and is increasing across a wide range of science-based topics, such as agriculture, evolution and genetics, vaccination, and climate change; even flat-earth beliefs are undergoing a renaissance. But in many of these areas, denying expert authority is cost-free in everyday behavior, making it more rational for people to prize identity and group affiliation over realism. To probe the health of expertise in a domain with everyday consequences for knowledge resistance, we conducted three incentive-compatible studies of laypeople's preferences for sources of information they would read about specific medical conditions (e.g., heart disease, cancer, COVID-19). We found quite rational preference patterns, by which people preferred sources based on experts (physicians and scientists) over non-experts (celebrities and politicians) and group consensus (professional societies, polls) over individual opinions. These findings held most strongly for issues of personal medical concern, but were robust for less concerning health conditions, and for the highly politicized topic of COVID-19. Individuals who scored higher in intellectual humility and preferences for rational over experiential thinking were more likely to prefer the most expert sources. Expertise retains broad respect in the medical domain, at least when one's own health is at stake.
\end{abstract}




\section{Introduction $^{1}$}

During the later years of his life, Mark Twain was asked by a journalist about rumors circulating that he was seriously ill and dying. "The report of my death was an exaggeration," he famously replied. In the past decade, the idea that expertise is dead, or at best moribund, has become commonplace (e.g., Freedman, 2010; Kakutani, 2018; Nichols, 2017; O’Connor \& Weatherall, 2019; Wikforss, 2017). It is true that experts are often overconfident in their own abilities: most professional stock pickers earn poorer returns than the market as a whole (Swedroe \& Berkin, 2020), and most political scientists and pundits are only slightly better at forecasting future world events than at forecasting coin flips (Tetlock, 2005). But when taken too far, a healthy skepticism of expert ability to predict specific future events can metastasize into indiscriminate disdain for expert knowledge. During the Brexit referendum campaign, for example, U.K. cabinet minister Michael Gove (2016) dismissed economic analyses of the referendum's consequences by saying "Britain has had enough of experts." Five years later it has become cliché for people to assert "I did my own research!" when they choose to disregard expert advice in favor of something they came across online. During the COVID-19 pandemic the Surgeon General of Florida, nominally an expert on public health, said residents "need to continue and stick with their intuition and their sensibilities" regarding the safety of vaccines (Blake, 2021).

Some accounts of the "death of expertise" and the rise of knowledge resistance note that it is less costly to be irrational with respect to matters of fact (or myth) that do not affect people personally and directly. Disregarding evidence for climate change or the impact of immigration is an option for many people because they perceive that their own lives and livelihoods are not

\footnotetext{
${ }^{1}$ We thank Matt Brown for his advice on this work, and participants in the Knowledge Resistance workshops for helpful comments. This research was supported by the Riksbankens Jubileumsfond grant "Knowledge Resistance: Causes, Consequences, and Cures" to Stockholm University, via a subcontract to Geisinger Health System.
} 
immediately at stake. Even entertaining the belief that the earth is flat (which a Google Books Ngram search suggests was at a 220-year peak in 2021) does not stop one from traveling safely to any location. The domain of medicine and health, however, is less abstract. Deciding whether to accept advice from physicians, researchers, and public authorities, can affect everyday health, as illustrated by cases of patients who put off vaccination, flouted mitigation guidelines, or put their trust in quack treatments, only to regret their decisions from their beds in Covid hospital wards (Healy, 2021).

However, public reactions to COVID-19 mitigation and vaccination efforts in the United States and other countries suggest that many do not always trust medical expertise. This is problematic insofar as trust in medical experts predicts following instructions that promote personal and public health. In 2020, the World Health Organization asserted that addressing the threat of COVID-19 would include managing an "infodemic," in which there was too much information available, with accurate information mixed with both accidentally and deliberately disseminated false or misleading information (World Health Organization, 2020). While public health professionals and institutions should have expertise in responding to viral epidemics, positive ratings for these experts have been declining in the United States (Robert Wood Johnson Foundation, 2021).

Many scientists argue that this reaction is not limited to COVID-19, which is a novel and still-unfolding situation. Polls and studies - mostly in the US, but also including some global reports - report low trust in science on some key issues like climate change, GMOs, and vaccinations (e.g., Funk et al., 2015; Funk et al., 2020b; Fagan \& Huang, 2019; Hornsey et al., 2018). For instance, there is a large gap between US adults and scientists with regards to the 
safety of genetically modified foods (51 percentage points), anthropogenic climate change (37 points), and human evolution (33 points; Funk et al., 2015).

In the U.S., many of the disagreements about these scientific issues have been attributed to ideological and political divides (e.g., Druckman \& McGrath, 2019; Kahan et al., 2012; 2017; Gauchat, 2011; Lee, 2021; Rekker, 2021). Discussions of anti-intellectualism in the US have been going on as far back as the 1960s (Hofstader, 1963), with evidence of decreasing trust in science — at least among political conservatives — since the 1970s (Gauchat, 2012). A survey of 14 countries shows that the political left (more than the political right) tends to trust that scientists are doing what is right for the public (Funk et al., 2015). When looking at specific topics like climate change, there is evidence of political divides outside the U.S., in countries like Australia (Tranter, 2011; Leviston et al., 2011) and the United Kingdom (Whitmarsh, 2011). However, this is not necessarily universal, as a study of newspapers in India found that $98 \%$ of the articles examined described climate change as anthropogenic, with several articles criticizing American climate change skeptics (Billett, 2008).

Aside from political affiliation, cross-cultural research on social media news use suggest that people in collectivist cultures with high power distance are more likely to trust science, since these cultures value the opinions of others and follow authority figures (Huber et al., 2019). A 24-country investigation of antivaccination attitudes similarly finds that people who have less individualist and more communitarian values tend to have more positive attitudes towards vaccination, as they are more willing to allow society and the government to make decisions for them (e.g., by mandating public health measures; Hornsey et al., 2018). Other geographical factors that may be associated with trust in science also include living in urban areas and being 
non-religious (Krause et al., 2019). There are also topic-specific factors, such as fear of needles and disgust about blood being associated with antivaccine attitudes (Hornsey et al., 2018).

With regards to how this lack of trust emerges, a large body of research has investigated motivated reasoning, where people accept, reject, and modify new information based on their prior beliefs or those of their group (e.g., Druckman \& McGrath, 2019; Kahan et al., 2012; 2017; Rekker, 2021). Findings from this work suggest that cognitive ability and scientific knowledge might ironically equip people to explain away new information that they do not agree with (Kahan et al., 2012). Research on misinformation and conspiratorial thinking suggests that a lack of careful and deliberative reasoning makes it more likely for people to uncritically accept and disseminate information that does not have proper scientific foundation (Bago et al., 2020; Pennycook et al., 2015; Pennycook \& Rand, 2021; Swami et al., 2014).

However, it might be unfair to paint the public's interactions with science and expertise with such a wide brush. Public opinion surveys in the U.S., Germany, and the U.K. have found overall confidence in science and scientists to be stable, if not increasing, over the past few years (American Academy of Arts and Sciences, 2018; Funk et al., 2019; Krause et al., 2019). In a survey of 20 countries, a majority of those surveyed said that they have at least some trust in scientists to do what is right (Funk et al., 2020b). In line with stable trust of scientists, public understanding of scientific topics, probability, and experimentation has remained stable in the U.S. over the past 20 years, according to regular surveys by the National Science Foundation (Besley \& Hill, 2020). Misinformation might also not have as strong of a grip as feared; a national survey of Democratic and Republican politicians found that regardless of their party's prior stances on genetically modified organisms, rent, and drug policies, policy makers from both parties revised their beliefs in the direction of presented evidence (Lee, 2021). 
While positive ratings of public health institutions have slightly declined, and trust in them was mixed during the COVID-19 pandemic (at one point only 52\% of those surveyed trusted the Centers for Disease Control and Prevention), around 70\% of people still trusted doctors and nurses, reflecting much greater trust than in friends and family (40\%; Robert Wood Johnson Foundation, 2021). This may reflect a more positive view of those who can remedy illness (e.g., frontline doctors) as opposed to those who prevent it (e.g., public health figures), especially if there isn't public consensus around the methods to mitigate the illness, and they include reducing individual liberty. This suggests that even if people might not trust all the experts available, there are apparently still some that most will listen to. It is not enough to group all scientists—or even those within a certain domain— - together.

Similarly, not all publicly contested scientific findings are equal. Recent concerns about the rejection of expertise have largely focused on topics that involve public policy (Bauer, 2009; Hotez, 2020; Rutledge, 2020; Scientific American, 2016). While political identification plays a role in how people listen to experts, researchers' perceptions about this problem might be driven by a vocal minority or a few contested topics. People and ideologies that reject experts might not be rejecting science or educated elites as a whole, but only certain claims or fields (Rekker, 2021). Research on the politicization of science has largely focused on a few "controversial" scientific topics such as anthropogenic climate change, evolution, and vaccinations, while disregarding others like cognitive ability and behavioral genetics. Even when looking at a set of ostensibly divisive topics, researchers found little partisan disagreement in many of them (McPhetres et al., 2019). Although there might be hotspots where expertise is politicized and fiercely challenged, overall trust in expertise might still be alive and well. And it should also be kept in mind that trust in science is in some ways blind. Research in cognitive science shows that 
acquiring and integrating scientific knowledge is not as rational and frictionless a process as we might assume. New facts and understandings coexist uneasily in the mind with ideas acquired earlier in life, with systematically biased perceptions of reality, and with anecdotes and myths, making it effortful and error-prone to follow science when its conclusions do not accord readily with our intuitions and common sense (e.g., Shtulman, 2017).

In light of these conflicting considerations, we conducted a series of three studies designed to assess the health of expertise in the domain of health itself. We attempted to measure whether and to what extent the general public would choose to access a broad variety of sources of expert medical advice. The domain of health and medicine is relevant to everyone, has clear indicia of expertise (e.g., medical degrees and specializations), established organizations that determine expert consensus (e.g., government institutions and professional societies), and highprofile information sources who are inside as well as outside the field (e.g., surgeon and talkshow host Dr. Mehmet Oz, actress and media entrepreneur Gwyneth Paltrow, and politicians). If phenomena such as the death of expertise (Nichols, 2017) and the rise of misinformation (Pennycook \& Rand, 2021) apply to healthcare, then people should be willing to seek unreliable sources about medicine and prioritize them over reliable ones.

Rather than simply ask participants how much they trusted different sources, a fairly abstract and general (though common) question, we offered them the opportunity to read an article from one of a dozen sources giving advice on how to manage a medical condition that personally concerned them. We then showed them the article they had chosen (in fact everyone was shown the same article for any given medical condition, as we did not want to spread nonexpert or biased advice to our participants) and asked them to read it before continuing in the study. In this sense our studies were more "incentive-compatible" than public opinion surveys, 
since there was a real (if small) consequence to participants for stating a preference for an information source. We also clustered ratings for different sources of expertise and evaluated their associations with individual differences in political identification, rational thinking, and intellectual humility, all of which might plausibly influence the degree to which people trust and attend to expert advice.

\section{Assessing Preferences for Sources of Expertise}

To assess people's preferences for different sources of medical expertise, we conducted three studies in 2019 and 2020 among almost 2000 online survey respondents in the United States. Respondents were recruited via Amazon Mechanical Turk (MTurk) using the Turkprime/CloudResearch service. Although none of the independent samples were recruited or weighted to be precisely representative of the U.S. population, each study included a fairly diverse sample of participants (see Table A1).

In Study $1(\mathrm{~N}=303$; data collected on March 3, 2019), we asked respondents to select one of several possible sources of information to read about a disease or medical condition that concerned them, and we asked them to rank the remaining sources to see how they prioritized them. In Study 2 ( $\mathrm{N}=265$; April 23-25, 2019), we tested whether people's preferences differed depending on how concerning the medical condition was to them. In Study $3(\mathrm{~N}=1431$; September 14-15, 2020), we recruited a much larger sample during the first resurgence of the COVID-19 pandemic in the U.S., and we took advantage of this unfortunate circumstance to examine whether people's preferences for health information sources were different for a novel, politicized health threat than for a well-understood but also very serious condition. 
In each study, respondents initially indicated whether they had a family history of eight common serious diseases and conditions: Alzheimer's disease, cancer, chronic kidney disease, chronic lung disease, diabetes, heart disease, obesity, and stroke. They then ranked these conditions based on how personally concerned they were about them. In Study 1, respondents were asked to think about the most concerning medical condition they selected. In Study 2, respondents were randomly assigned to think of either their most or least concerning medical condition from that list. In Study 3, we randomly assigned respondents to think about either cancer — which had ranked as the most concerning medical condition from Studies 1 and 2 - or COVID-19.

Respondents in each study were next given the opportunity to read an article with tips on how to reduce the risk of getting the medical condition they selected (Study 1) or to which they were assigned (Studies 2-3). They were then given a choice of 12 sources (Studies 1-2) or 14 sources (Study 3) of information for this article, with the implication that each source was actually the author or creator of the article they would get to see. We selected a variety of sources that varied in the type of source: individual figure, institution, or representative survey of individuals. Individual sources also had varying characteristics (e.g., physician, scientist, journalist, layperson, celebrity). We gave fictional names for the physicians, the journalist, the scientist, and the pharmaceutical company, and used real names for the celebrities, politicians, government institute, and medical professional societies. For consistency, we made all individually-named persons male (with the exception of Gwyneth Paltrow, who we believe did not have an equally-popular male counterpart). Table 1 shows the specific sources offered in the three studies, as they were described to participants. 
Table 1. List of sources of expertise used in Studies 1-3.

\begin{tabular}{|c|c|}
\hline Source of expertise & Description provided to respondents \\
\hline $\begin{array}{l}\text { Physician in a relevant domain (e.g., cardiologist if } \\
\text { randomized to heart disease) }\end{array}$ & $\begin{array}{l}\text { information from Dr. Brian Davis, a doctor } \\
\text { specializing in [medical condition] }\end{array}$ \\
\hline $\begin{array}{l}\text { Physician in an irrelevant domain (e.g., podiatrist if } \\
\text { randomized to heart disease) }\end{array}$ & $\begin{array}{l}\text { information from Dr. Ryan Wilson, a doctor } \\
\text { specializing in skin disease }\end{array}$ \\
\hline Journalist in a relevant domain & $\begin{array}{l}\text { information from Stephen Green, a journalist who } \\
\text { primarily writes about [medical condition] }\end{array}$ \\
\hline Scientist in a relevant domain & $\begin{array}{l}\text { information from Alex Miller, a research scientist } \\
\text { who primarily studies [medical condition] }\end{array}$ \\
\hline Survey of the general public & $\begin{array}{l}\text { information based on a representative survey of } \\
1000 \text { members of the general public }\end{array}$ \\
\hline Survey of doctors & $\begin{array}{l}\text { information based on a representative survey of } \\
1000 \text { doctors }\end{array}$ \\
\hline Survey of patients & $\begin{array}{l}\text { information based on a representative survey of } \\
1000 \text { people with [medical condition] }\end{array}$ \\
\hline Government Health Institute & $\begin{array}{l}\text { information from the National Institutes of Health, } \\
\text { a government medical research center }\end{array}$ \\
\hline $\begin{array}{l}\text { Drug company that makes products for the target medical } \\
\text { condition }\end{array}$ & $\begin{array}{l}\text { information from LBY Medical Innovations, a } \\
\text { company that develops products for people with } \\
\text { [medical condition] }\end{array}$ \\
\hline $\begin{array}{l}\text { Medical professional society for those specializing in the } \\
\text { target medical condition (e.g., the American College of } \\
\text { Cardiology for heart disease) }\end{array}$ & $\begin{array}{l}\text { information from [professional society], a society } \\
\text { of health professionals specializing in [medical } \\
\text { condition] }\end{array}$ \\
\hline $\begin{array}{l}\text { Celebrity physician (Dr. Mehmet Oz of the television } \\
\text { program "The Dr. Oz Show") }\end{array}$ & $\begin{array}{l}\text { information from Dr. Mehmet Oz, host of the Dr. } \\
\text { Oz Show on TV }\end{array}$ \\
\hline $\begin{array}{l}\text { Celebrity non-physician (Gwyneth Paltrow of the lifestyle } \\
\text { company Goop) }\end{array}$ & $\begin{array}{l}\text { information from Gwyneth Paltrow, actress and } \\
\text { owner of the lifestyle company Goop }\end{array}$ \\
\hline Study 3 only: Republican Politician & $\begin{array}{l}\text { information from Republican Senator Mike Braun, } \\
\text { a member of the Committee on Health, Education, } \\
\text { Labor, and Pensions }\end{array}$ \\
\hline Study 3 only: Democratic Politician & $\begin{array}{l}\text { information from Democratic Senator Doug Jones, } \\
\text { a member of the Committee on Health, Education, } \\
\text { Labor, and Pensions }\end{array}$ \\
\hline
\end{tabular}

Note: Within each study, every participant saw the sources listed in a randomized order. 
We did not follow a systematic design when devising these sources of information; rather, our selection was motivated by the following questions: Are medical sources prioritized over nonmedical sources? Are specialists in a sub-domain prioritized over generalists? How do the consensus or polled opinions of large groups of people rank compared to other sources of information (as research on collective intelligence suggests they should be; e.g., Surowiecki, 2004; Wolf et al., 2015)? Are celebrity sources — expert or non-expert—prioritized over noncelebrity sources? Are individuals or groups prioritized as a source of information? It should however be noted that we did not design the studies to have statistical power for directly testing each of these questions. Instead, we intended to look at overall patterns.

After selecting a source to read, respondents in Study 1 were asked to rank the remaining sources. In Studies 2 and 3, we also asked respondents to rate all sources on 1-5 Likert-type scales for (1) how helpful they were as a source of medical information, (2) how much they trusted that source as a source of information about their assigned medical condition, and (3) how curious they were to read the article from that source. Across Studies 2-3, ratings in response to these three items correlated with high reliability (Cronbach's alphas: .71-.87); for analysis we collapsed them into a single score rating the "quality" of the source.

After rating or ranking the sources, respondents were shown the article. The article was ostensibly written by their chosen source, but for each medical condition it was a standardized article that we wrote using readily available recommendations from medical professional societies and government health institutes regarding that condition. Respondents then answered some questions about the article and their familiarity with the celebrity sources mentioned. In Studies 2 and 3, respondents also filled out the Rational-Experiential Inventory 10 (REI-10; Norris et al., 1998), a scale of the habitual tendency to use rational/analytical or 
experiential/intuitive thinking styles (Pacini \& Epstein, 1998), and the General Intellectual Humility Scale (GIHS; Leary et al., 2017). We included these scales to assess individual differences in reasoning styles and intellectual humility, both of which might be associated with less biased choices in sources (Leary et al., 2017; Pennycook \& Rand, 2021). ${ }^{2}$

\section{General Preferences for Sources of Medical Expertise}

As seen in Figure 1, in all three studies, participants most commonly chose to read advice from the medical professional society relevant to their condition. While the specific rank-order of the next six sources varied from study to study, the top seven preferences all had legitimate expertise or personal experience with the medical condition. The top six preferences were chosen by $94.5 \%, 79.1 \%$, and $89.9 \%$ of the respondents in studies $1-3$, respectively.

While the celebrity physician (Dr. Mehmet Oz) was ranked 7th in all three studies, fewer people chose him as a first choice in Study 3. It is worth noting that Dr. Oz's daily television show has been reported to give medical advice that is supported only one-third of the time by "somewhat believable" or "believable" evidence (Korownyk et al., 2014). However, Dr. Oz is a cardiothoracic surgeon by training and could be considered an expert in that domain. With that in mind, we looked at the rankings excluding people who were selecting a source to read about heart disease and chronic lung disease, and found a similar pattern.

The non-expert celebrity, actress and entrepreneur Gwyneth Paltrow, is a popular source for lifestyle, beauty, and health advice whose programs can be found on Netflix and whose magazines are sold in supermarkets across the U.S. Given her popularity and her reputation for

\footnotetext{
${ }^{2}$ More detailed protocols for these three studies, along with complete materials, survey text, raw data, and R code for analysis, are available at the Open Science Framework (https://osf.io/jmcp7/).
} 
dispensing pseudoscientific or even dangerous advice (Caulfield, 2015), we were both surprised and relieved to find that she ranked last or third-to-last in all three studies.

Overall, our findings suggest that the majority of respondents look to medical professionals or to patients with first-hand experience of their concerning medical condition, with most people choosing a society of medical professionals. The society of medical professionals is arguably the best choice offered, as a recommendation from them represents a consensus of experts as opposed to a potentially idiosyncratic individual physician, or a group of physicians who are not specialists in their medical condition. Although a journalist in a relevant domain should also be a credible source, respondents preferred medical professionals. Likewise, a company that makes products addressing a medical condition should have access to much expertise on that condition, but respondents consistently ranked pharmaceutical companies near the bottom, perhaps assuming they are biased by commercial interests.

\section{Figure 1. Overall preferences for source of medical information (percentage).}
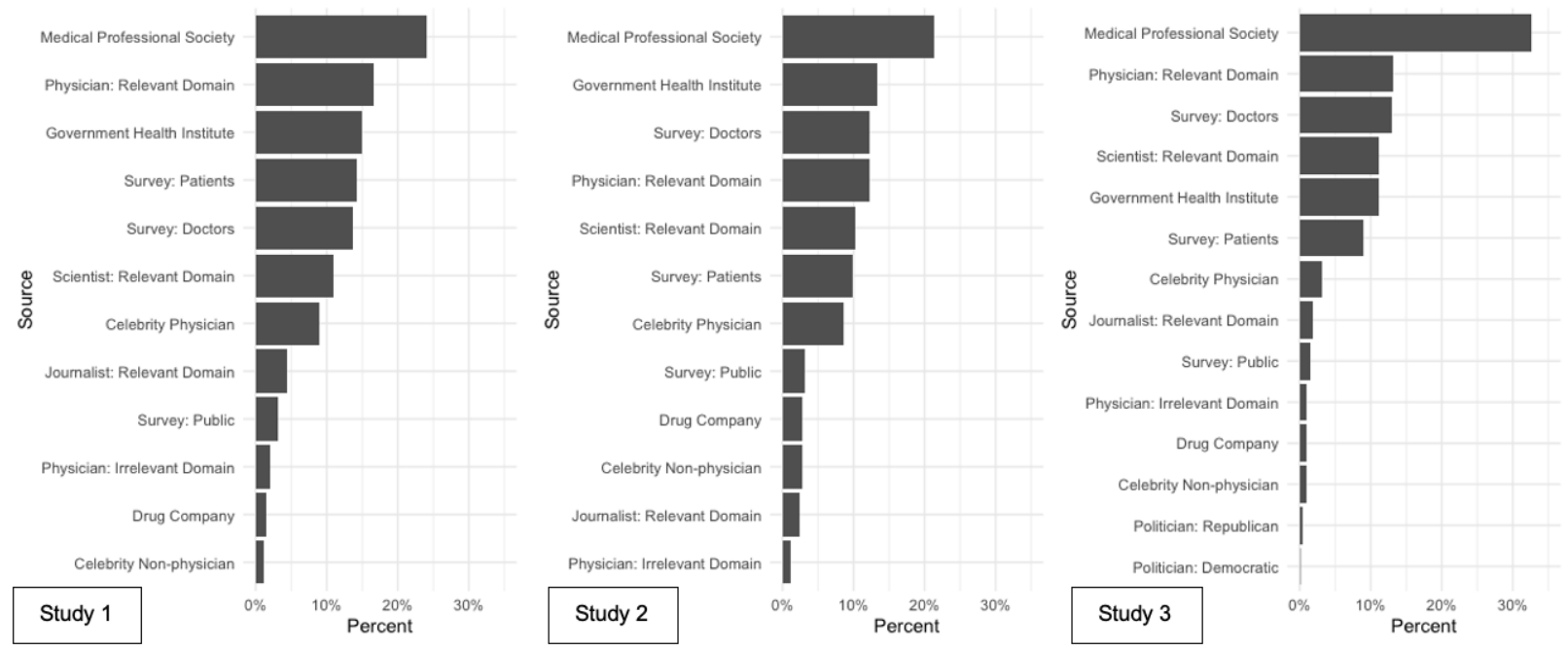

Note: The figure shows the percentage of study participants choosing to read an article about their assigned medical condition from each of 12 (Study 2) or 14 (Study 3) sources offered. 
In Studies 2 and 3, we experimentally manipulated whether the medical condition was of highest or lowest concern (Study 2) and whether it was cancer or COVID-19 (Study 3). We thought that respondents might be more motivated to discern between good and bad sources in conditions of high concern, or more likely to select politicized sources for COVID-19, which we also assumed was of higher concern to our average participant than cancer during late 2020 . However, these manipulations had relatively small effects on participant preferences. As shown in Figure 2, the high-concern and low-concern conditions both had the same top seven information sources, although the most popular among people in the low-concern group was a medical professional society, while the most popular among the high-concern group was a representative sample of doctors. (We note that the pattern observed with the high-concern group in Study 2 did not completely replicate the pattern from Study 1, in which all respondents were asked to think about the medical condition they had ranked as most concerning to them: For the high-concern group in Study 2, preferences among the top seven sources spread out more evenly, with no clear top preference.)

In Study 3, we found that a medical professional society was the top source both for respondents assigned to think about cancer and those assigned to think about COVID-19. Perhaps reflecting the fact that COVID-19 was a novel medical condition with less time for experts to achieve consensus, we found that the distance between the top source and other sources was larger with cancer). 
Figure 2. Preferences for source of medical information by experimental condition (percentage).
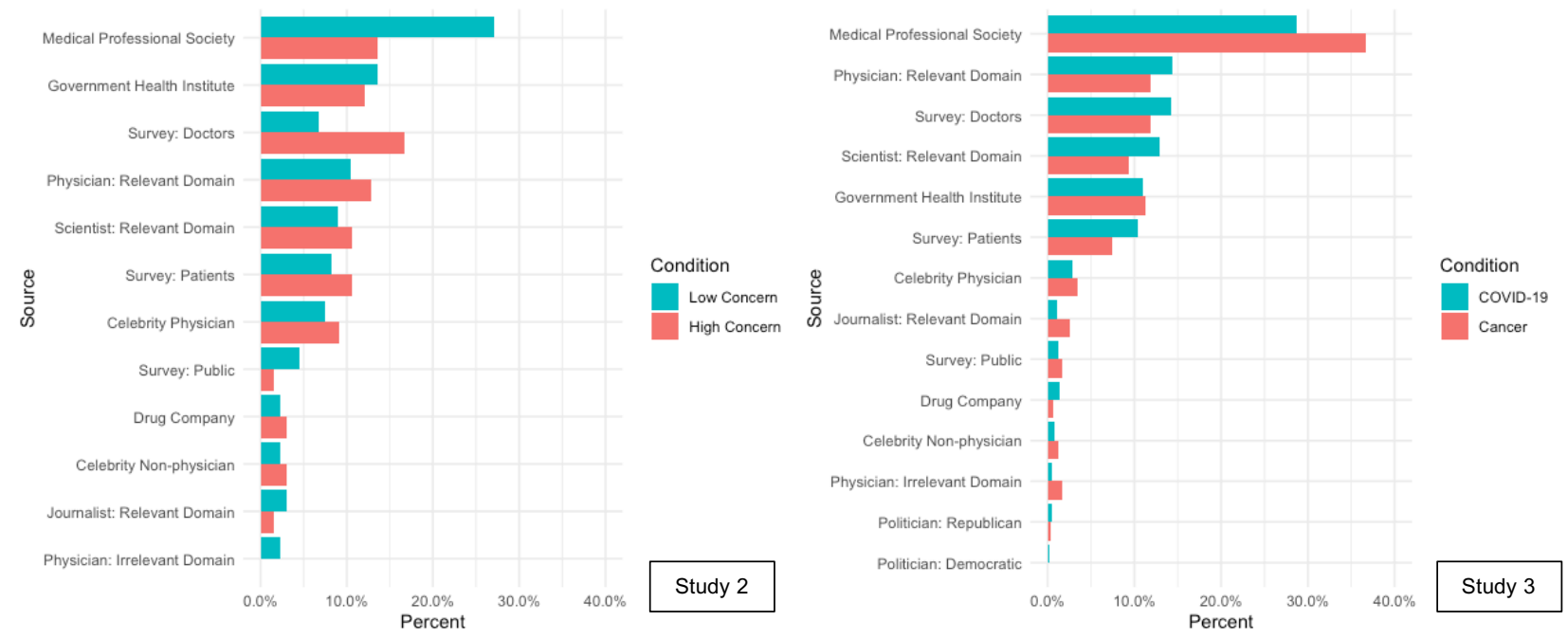

Note: The figure shows the percentage of study participants choosing to read an article about their assigned medical condition from each of 12 (Study 2) or 14 (Study 3) sources offered.

Looking beyond top preferences, we examined the mean rankings that respondents gave all the sources in Study 1 (see Figure 3). Here we found a similar pattern for the top six sources, with domain-specific experts and groups of medical experts or patients who have experienced the medical condition being ranked, on average, higher than the rest of the sources. However, among the top sources, there was little difference in mean rankings. Note that while there was a substantial preference for the medical professional societies when people were asked to choose just one source, this effect was much smaller with rankings. 


\section{Figure 3. Mean ranking of sources of medical information in Study 1.}

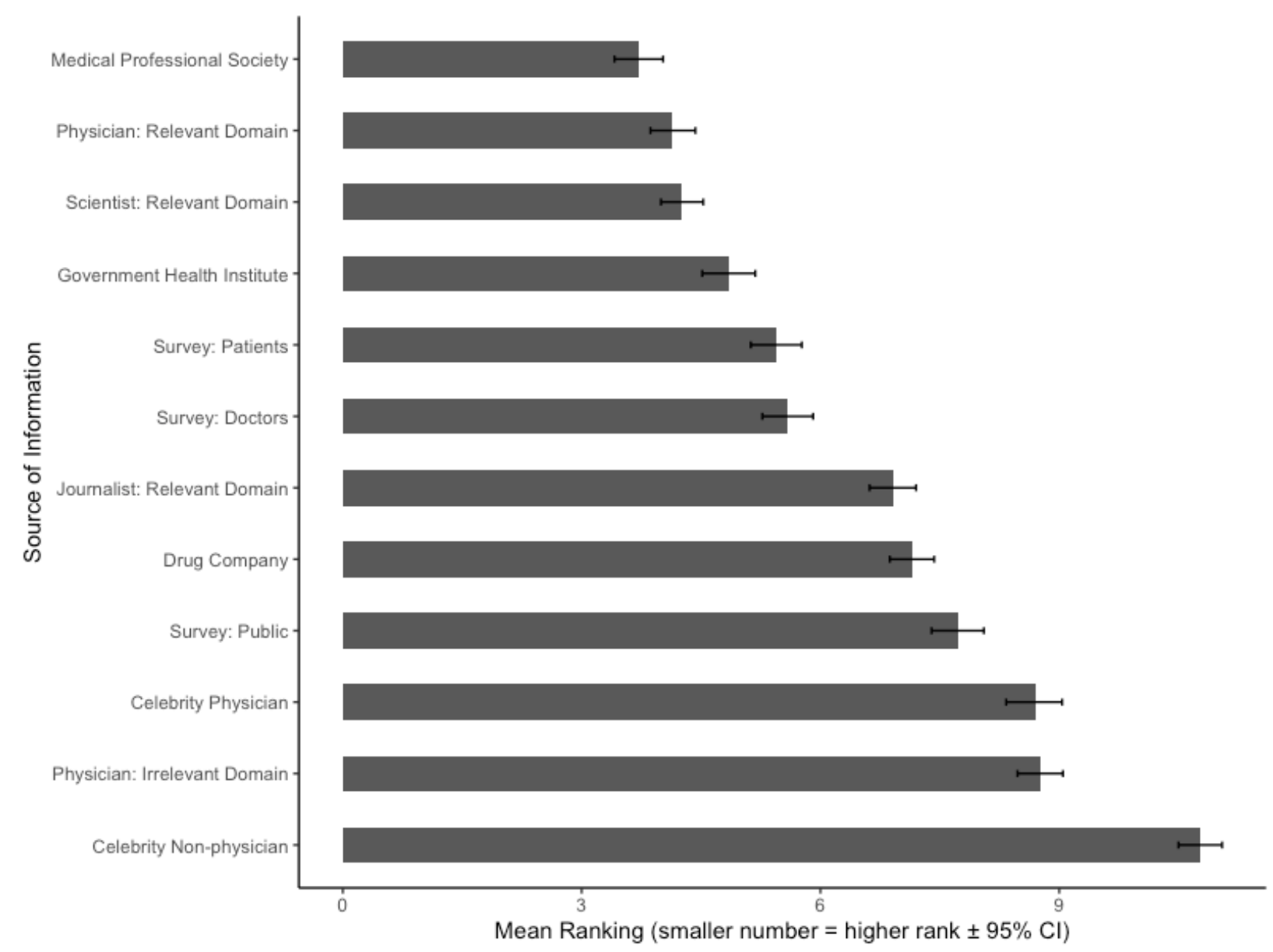

\section{Clustering Sources of Expertise}

To systematically categorize the different sources in Studies 2 and 3 and to reduce the ratings for 12 or 14 sources into a more manageable number of dimensions, we conducted exploratory factor analyses. In factor analyses, the assumption is that there is a set of underlying, unobserved variables - or factors - that can explain the relationships among the measured variables. For instance, if we find that a set of sources are all rated in a similar way, this suggests that there is a theme uniting those sources, that they are perceived and understood as having something in common. As we did not have defined groupings of the sources a priori, factor analysis is a data- 
driven way of seeing what sources cluster together based on the quality ratings respondents gave them.

For both studies, we used principal components analysis with oblique rotation (which allows the inferred factors to be somewhat correlated with one another, rather than completely independent), and we found three factors (with Eigenvalues greater than 1. After examining which sources loaded onto the different factors (see Table 2), we found similar factor groupings in Studies 2 and 3, and designated the factors "Expert sources," "Survey sources," and "Less reliable sources."

Table 2. Standardized factor loadings for ratings of sources in Studies 2 and 3.

\begin{tabular}{|c|c|c|c|c|c|c|}
\hline & \multicolumn{3}{|c|}{ Study 2} & \multicolumn{3}{|c|}{ Study 3} \\
\hline & $\begin{array}{r}\text { Expert } \\
\text { Sources }\end{array}$ & $\begin{array}{c}\text { Survey } \\
\text { Sources }\end{array}$ & $\begin{array}{r}\text { Less Reliable } \\
\text { Sources }\end{array}$ & $\begin{array}{r}\text { Expert } \\
\text { Sources }\end{array}$ & $\begin{array}{c}\text { Survey } \\
\text { Sources }\end{array}$ & $\begin{array}{r}\text { Less Reliable } \\
\text { Sources }\end{array}$ \\
\hline $\begin{array}{l}\text { Medical Professional } \\
\text { Society }\end{array}$ & .82 & .14 & -.18 & .86 & -.03 & -.06 \\
\hline $\begin{array}{l}\text { Physician: } \\
\text { Relevant Domain }\end{array}$ & .87 & -.05 & .05 & .85 & .07 & -.70 \\
\hline $\begin{array}{l}\text { Scientist: } \\
\text { Relevant Domain }\end{array}$ & .86 & .05 & -.01 & .83 & .08 & -.02 \\
\hline $\begin{array}{l}\text { Government } \\
\text { Institution }\end{array}$ & .57 & .41 & -.09 & .77 & -.12 & .18 \\
\hline Survey: Physicians & .20 & .82 & -.05 & .33 & .60 & -.02 \\
\hline Survey: Patients & .12 & .77 & -.04 & .02 & .91 & -.07 \\
\hline Survey: Public & -.28 & .72 & .35 & -.18 & .65 & .36 \\
\hline Journalist & .61 & -.03 & .50 & .43 & .16 & .40 \\
\hline Drug Company & .45 & -.02 & .66 & .31 & .27 & .44 \\
\hline $\begin{array}{l}\text { Physician: } \\
\text { Irrelevant Domain }\end{array}$ & .01 & .36 & .54 & .24 & -.05 & .62 \\
\hline
\end{tabular}




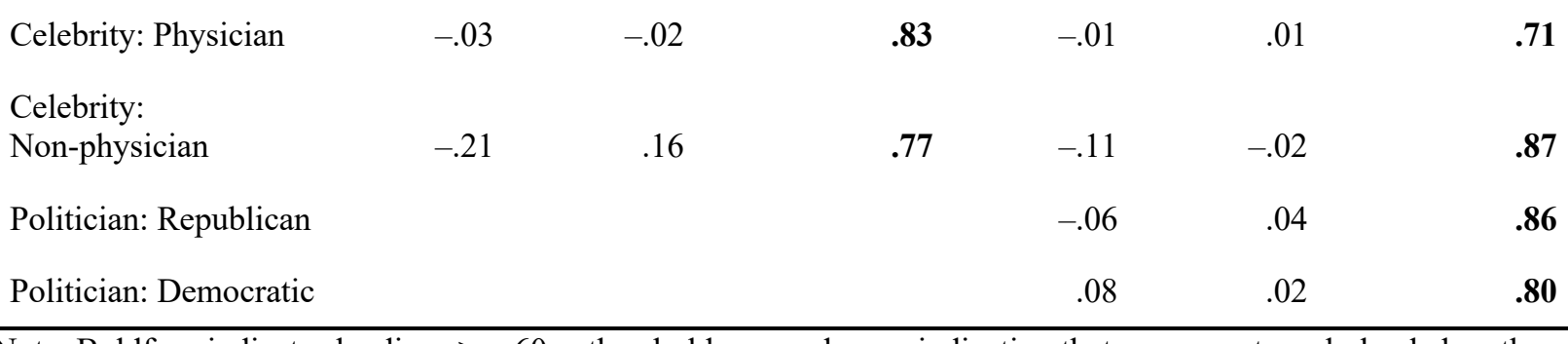

Note: Boldface indicates loadings $>=.60$, a threshold we used as an indication that a source strongly loaded on the factor.

In Study 2, one factor (explaining $28 \%$ of the variance in the model) consisted of domainspecific expert sources: the physician in a relevant domain, the scientist in a relevant domain, and the medical professional society Another factor (19\% of variance) consisted of the surveys of physicians, public, and patients with the medical condition. The remaining factor $(21 \%$ of variance) consisted of less reliable sources: the drug company, the celebrity physician, and the celebrity non-physician. The government institution cross-loaded onto the expert and survey factors, which suggests that an underlying theme in both explains the variation in the ratings for the government institution. Similarly, the doctor in an irrelevant domain cross-loaded onto the survey and less-reliable sources factors.

In Study 3, the expert sources factor (24\% of variance) consisted of the physician in a relevant domain, the scientist in a relevant domain, the medical professional society, and the government institution. The survey factor (14\% of variance) consisted of the physician, public, and patient surveys. And the less reliable sources factor (27\% of variance) consisted of the celebrity physician, the celebrity non-physician, the Republican senator, the Democratic senator, and the doctor in an irrelevant domain. Here, the journalist and the drug company cross-loaded on all three factors. 


\section{Correlates of Trust in Different Sources of Expertise}

To examine individual differences in rating these sources, we also looked at the correlations between mean ratings of experts grouped by the three factors, politics, the habitual use of rational/analytical thinking or experiential/intuitive thinking as measured by the REI-10 (Norris et al., 1998; Pacini \& Epstein, 1998), and intellectual humility as measured by the GIHS (Leary et al., 2017). We expected that respondents high in rational/analytical thinking and intellectual humility would be more likely to rate expert sources high and less-reliable sources low. Given that misinformation about COVID-19 and resistance against health measures like masking and vaccines have often come from the political right (Kempthorne \& Terrizzi, 2021), we expected to find lower ratings of expert sources and higher ratings of less-reliable sources among political conservatives and Republicans. In Studies 2 and 3, we included a single-item measure of political ideology from liberal (1) to conservative (5). In Study 3, we added a measure of party affiliation, ranging from strongly Democratic (1) to strongly Republican (7).

As shown in Table 3, expert sources were given high ratings by those with higher intellectual humility while less-reliable sources were given low ratings by those who scored higher on the REI-10, which indicated a habitual preference for rational/analytical thinking over experiential/intuitive thinking. In study 3 , we also found that rational/analytical thinking, being politically liberal, and affiliating with the Democratic party were positively associated with higher ratings for expert sources. Greater self-identification as conservative (but not necessarily Republican) correlated with higher ratings of less-reliable sources in Study 3. Notably, we also found a similar pattern when focusing only on COVID-19. Higher scores for the survey sources were positively associated with less rational/analytical thinking, greater intellectual humility, and a more conservative (but not necessarily Republican) political identification. 
Table 3. Correlation between factor scores and preference for rational over experiential thinking, intellectual humility, and political views in Studies 2 and 3.

\begin{tabular}{lllllll}
\hline & \multicolumn{3}{c}{ Study 2} & \multicolumn{3}{c}{ Study 3} \\
\hline & $\begin{array}{l}\text { Expert } \\
\text { Sources }\end{array}$ & $\begin{array}{l}\text { Survey } \\
\text { Sources }\end{array}$ & $\begin{array}{l}\text { Less Reliable } \\
\text { Sources }\end{array}$ & $\begin{array}{l}\text { Expert } \\
\text { Sources }\end{array}$ & $\begin{array}{l}\text { Survey } \\
\text { Sources }\end{array}$ & $\begin{array}{l}\text { Less Reliable } \\
\text { Sources }\end{array}$ \\
& & & & & & \\
\hline $\begin{array}{l}\text { Rational-Experiential } \\
\text { Inventory (Rational) }\end{array}$ & .02 & .04 & $-.18^{*}$ & $.07^{*}$ & $-.11^{* * *}$ & $-.10^{* * *}$ \\
Intellectual Humility & $.38^{* * *}$ & .12 & -.07 & $.35^{* * *}$ & $.11^{* * *}$ & .02 \\
$\begin{array}{l}\text { Political ideology } \\
\text { (Conservative) }\end{array}$ & & & & & & .02 \\
Political Party (Republican) & N/A & N/A & N/A & $-.16^{* * *}$ & .02 & .01 \\
\hline
\end{tabular}

Note: ${ }^{*} \mathrm{p}<.05, * * \mathrm{p}<.01, * * * \mathrm{p}<.001$.

The results from the overall ranking of sources and ratings of factors suggest that people prefer to consult domain-specific expert sources for medical information. The clear preference for medical professional societies across all three studies suggests that people prioritized a consensus of experts - or at least that the organizations mentioned are easily-accessible and trusted sources. These findings support recent polls showing that scientists are among the most trusted leadership groups (American Academy of Arts and Sciences, 2018). These polls also provide some explanation for the relatively lower rankings of journalists and the pharmaceutical company despite their domain-specific expertise; only around half of those polled are confident that these groups will act in the best interests of the public (Funk et al., 2019).

Ratings for the sources in Studies 2 and 3 coalesced into three fairly distinct clusters. While there were some differences among weakly-loading sources, the composition of the clusters was mostly consistent between the studies. The sources consistently in the expert sources factor are the professional medical society, doctors specializing in the target medical condition, 
and scientists studying the target medical conditions - all of whom are domain-specific experts. The three survey sources were also grouped together. The sources that were consistently in the less reliable sources cluster were the celebrity physician and non-physician; depending on the study, the drug company, physician in a different specialty, and the Republican and Democratic senators were also part of this group. While there was not a strong theme uniting all of these sources, we labelled them as the "less reliable" sources as they generally do not possess clear domain-specific expertise and would be judged by professional standards as unreliable.

In Study 3, we furthermore found evidence that those who identify as politically liberal and Democratic give higher quality ratings to expert sources and lower ratings to less reliable sources. These findings support polls and studies which have found that trust in scientists is lower for political conservatives (Funk et al, 2019, but also see McPhetres et al., 2019). The correlations with political ideology were not as strong in Study 2, which was conducted before the COVID-19 pandemic, suggesting that polarization of trust in experts might have increased in the U.S. (Funk et al., 2020a).

The strongest correlate of giving high ratings to expert sources and survey sources (in Study 3 ) is the trait of intellectual humility, which is the tendency to recognize that one's personal beliefs or knowledge might be limited (Leary et al., 2017). More than simply being open to recommendations of experts, people with high intellectual humility are more open to and less threatened by alternative information, which could reduce the likelihood of confirmation bias (Porter \& Schumann, 2018). They are also more sensitive to the persuasive strength of arguments and as a result might also be more discerning about the sources of information they trust (Leary et al., 2017). 
While humility encourages people to value expert sources, rational/analytical thinking as measured by the REI-10 was associated with devaluing the less-reliable sources. This aligns with findings showing that people who reason analytically are more skeptical of paranormal and conspiratorial claims (Pennycook et al., 2015; Swami et al., 2014), more likely to distinguish between false and true news headlines (Bago et al., 2020), and less susceptible to biases (Lu, 2015; Toplak et al., 2011). People who report a greater preference for rational/analytical thinking might take more time to pick the best source and be less swayed by confirmation bias, familiarity, and other peripheral cues of the quality of the source. While certainly not exhaustive (see Pennycook \& Rand, 2021; Pornpitakpan, 2004), our findings suggest that a combination of political identity and cognitive factors may play a role in source selection. Nonetheless, these effects of individual differences merely modulate strong general preferences among all participants for high-quality sources of medical information about health conditions of concern.

\section{Limitations of this Investigation}

In light of the broader discussion about the death of expertise, it is important to note that our investigation focused on medical expertise, which is generally respected and trusted in the U.S. When asking respondents to choose and rate their sources, we furthermore did not present hotly contested and politicized topics like vaccinations and masking, and did not name sources that were at the forefront of the media related to COVID-19 like Dr. Anthony Fauci and the Centers for Disease Control. While our investigation might be generalizable, as we found similar effects before and during the COVID-19 pandemic, it is thus unclear if this pattern would hold if a similar study directly mentioned controversial aspects of the response to COVID-19 or other 
politicized medical topics. Further, as the COVID-19 pandemic is a protracted and still-unfolding situation, the U.S. public's trust of experts on this topic may continue to change.

Despite our efforts to present a plausible interaction with experts in our study, there are also key differences between our online survey and real-world situations in which people would receive information from experts. While we did offer the respondents names of the sources and eventually showed them an ostensibly real article, respondents knew that they were in a research study and could have treated the scenario as hypothetical or suspected that we expected them to respond "rationally." In addition, in reality most people are not offered multiple sources of information juxtaposed next to each other, as though they were in an intellectual supermarket with medical society reports sharing shelf space with news articles, pharmaceutical ads, and celebrity TV shows. In a social media feed or news on TV, there is often only one messenger or attributed source of information available at any one time - if any real source is provided at all.

Further, there was little context given to the sources we offered. Only the name and a brief description were provided, such as "Dr. Brian Davis, a doctor specializing in heart disease." Arguably, respondents were making selections based on the prototypical role or title rather than distinctive details about each source. They were not given the opportunity to review credentials or the quality of their arguments. As a result, our investigation was able to capture a surface-level interaction with fairly abstract expert sources. However, this lack of depth might not be very different from how people select sources to attend from the deluge of data in their daily lives. For instance, our investigation can still provide insights on how people could be influenced by social media posts, emails from work, or news stories depending on who the messenger was.

Nevertheless, as with all experiments, these limitations should be kept in mind. 


\section{Conclusions}

In the comedy film Monty Python and the Holy Grail, which still has much to teach viewers about logical reasoning and critical thinking, an early scene opens on a wooden cart piled with bodies being pushed through a muddy road during a medieval plague. "Bring out yer dead" yells the cart driver. A villager drags out a man's body and puts it on the cart, paying the driver's fee to take it away. But the man is still alive. "I'm not dead!" he protests. After a lengthy discussion, the cart driver realizes he can get around the regulations on hauling off live bodies by clubbing the man to death, which he does. The results of our three studies, in which U.S. participants generally selected sources of information in a surprisingly rational pattern consistent with respect for expert authority, suggest that expertise is not yet dead — at least when it comes to medical conditions that people are concerned about_-but that it might yet be murdered by people who would profit by doing so.

At a minimum, our finding puts a boundary around the "death of expertise" concept, and shows that to the extent it applies, it does not apply equally to all domains or issues. While we did not study any areas other than medicine, we are confident that if we had conducted similar studies on whether people preferred trained pilots for their flights, credentialed structural engineers for their bridges, or nuclear physicists for their power plants, they would almost uniformly agree that expertise is alive and well.

However, the general respect people showed for medical experts in our studies also reveals a weak point that agents seeking to manipulate public opinion, even in the health domain, could exploit. Passing along pseudoscience or fake news under the name of an alleged authority, made-up institution, or hastily-convened group of experts (such as the "Front Line COVID-19 Critical Care Alliance" that promoted the drug ivermectin as a treatment for coronavirus 
infection; Huang, 2021) is likely to trick at least some people who think they are being careful in their information consumption habits. For instance, trust in science can ironically encourage belief in and dissemination of pseudoscientific information when it is accompanied by attractive graphics, references and other trappings of quality scientific research. Appealing to the value of science does not attenuate this effect, but encouraging critical evaluation does (O'Brien et al., 2021). Respected sources of expertise can be used as vectors for misinformation; our results show why this can be expected to continue to work, at least until the practice degrades trust in true experts so much that it no longer works. Thus, ironically, the death of true expertise could also kill our willingness to fall for fake expertise.

Our results do point to intellectual humility as a potential antidote to the derogation of expertise. People need to find trusted sources, and they also need to maintain trust when experts make mistakes or change their course (Leary, 2017). In politics, changing one's mind is (unfortunately) most often regarded as a sign of weakness, inauthenticity, or flip-flopping; increasingly those norms are being applied to experts outside of politics. With increasing access to science and particularly in the wake of COVID-19 people have become more exposed to the messy, multifaceted, and changing nature of scientific evidence and the recommendations and policies that are informed by it. While the search for accuracy is laudable, people do not have the time to become knowledgeable enough in every field that requires decisions (Kahan, 2017). Thus, intellectual humility — and related qualities like openness, wisdom, and a preference for rational thinking (Pinker, 2021)—might help people make judicious decisions in the face of changing expert advice. 


\section{References}

American Academy of Arts and Sciences. (2018). Perceptions of Science in America. https://www.amacad.org/sites/default/files/publication/downloads/PFoS-Perceptions-ScienceAmerica.pdf

Bago, B., Rand, D. G., \& Pennycook, G. (2020). Fake news, fast and slow: Deliberation reduces belief in false (but not true) news headlines. Journal of Experimental Psychology: General, 149(8), 1608-1613.

Bauer, M. W. (2009). The evolution of public understanding of science: Discourse and comparative evidence. Science, Technology and Society, 14(2), 221-240.

Blake, A. (2021, October 21). Ron DeSantis's controversial surgeon general questions safety of vaccines. The Washington Post. https://www.washingtonpost.com/politics/2021/10/21/ron-desantiss-controversial-surgeongeneral-questions-safety-vaccines/

Besley, J. C. \& Hill, D. (2020, May). Science and technology: Public attitudes, knowledge, and interest. https://ncses.nsf.gov/pubs/nsb20207

Billett, S. (2010). Dividing climate change: Global warming in the Indian mass media. Climatic Change, 99, 1-16.

Caulfield, T. (2015). Is Gwyneth Paltrow wrong about everything? How the famous sell us elixirs of health, beauty and happiness. Beacon Press.

Daly, M., Jones, A., \& Robinson, E. (2021). Public trust and willingness to vaccinate against COVID-19 in the US From October 14, 2020, to March 29, 2021. Journal of the American Medical Association, 325(23), 2397-2399. 
Druckman, J.N. \& McGrath, M.C. (2019). The evidence for motivated reasoning in climate change preference formation. Nature Climate Change, 9(2), 111-119.

Editorial Board (2016, September 01). Donald Trump's lack of respect for science is alarming. Scientific American. https:/www.scientificamerican.com/article/donald-trump-s-lackof-respect-for-science-is-alarming/

Fagan, M. \& Huang, C. (2019, April 18). A look at how people around the world view climate change. https://www.pewresearch.org/fact-tank/2019/04/18/a-look-at-how-peoplearound-the-world-view-climate-change/

Freedman, D.H. (2010). Wrong: Why experts keep failing us-and how to know when not to trust them. Little, Brown.

Funk, C., Ranie, L., \& Page, D. (2015, January 29). Public and scientists' view on science and society. https://www.pewresearch.org/science/2015/01/29/public-and-scientistsviews-on-science-and-society/

Funk, C., Heffernon, M., Kennedy, B., \& Johnson, C. (2019, August 2). Trust and mistrust in Americans' views of scientific experts.

https://www.pewresearch.org/science/2019/08/02/trust-and-mistrust-in-americans-views-ofscientific-experts/

Funk, C., Kennedy, B., \& Johnson, C. (2020a, December 17). Trust in medical scientists has grown in U.S., but mainly among Democrats. https://www.pewresearch.org/science/2020/05/21/trust-in-medical-scientists-has-grown-in-u-sbut-mainly-among-democrats/

Funk, C., Tyson, A., Kennedy, B., \& Johnson, C. (2020b, September 29). Science and scientists held in high esteem across global publics. 
https://www.pewresearch.org/science/2020/09/29/science-and-scientists-held-in-high-esteemacross-global-publics/

Gardner, D. (2011). Future babble: Why expert predictions are next to worthless, and you can do better. Dutton.

Gauchat, G. (2012). Politicization of science in the public sphere: A study of public trust in the United States, 1974 to 2010. American Sociological Review, 77(2), 167-187.

Gove, M. (2016, October 21). "Experts" like Carney must curb their arrogance. The Times. https://www.thetimes.co.uk/article/experts-like-carney-must-curb-their-arrogancejkffvjlzm

Healy, J. (2021, July 30). They spurned the vaccine. Now they want you to know they regret it. The New York Times. https://www.nytimes.com/2021/07/30/us/covid-vaccinehesitancy-regret.html

Hofstadter, R. (1963). Anti-intellectualism in American life. Vintage.

Hornsey, M. J., Harris, E. A., \& Fielding, K. S. (2018). The psychological roots of antivaccination attitudes: A 24-nation investigation. Health Psychology, 37(4), 307-315.

Hotez P. J. (2020). Combating antiscience: Are we preparing for the 2020s? PLoS Biology, 18(3), e3000683.

Huang, P. (2021, September 19). How Ivermectin became the new focus of the antivaccine movement. National Public Radio. https://www.npr.org/sections/healthshots/2021/09/19/1038369557/ivermectin-anti-vaccine-movement-culture-wars

Huber, B., Barnidge, M., Gil de Zúñiga, H., \& Liu, J.H. (2019). Fostering public trust in science: The role of social media. Public Understanding of Science, 28, 759-777. 
Kahan, D. (2017). On the sources of ordinary science knowledge and extraordinary science ignorance. In K. H. Jamieson, D. Kahan, \& D. A. Scheufele (Eds.), The Oxford handbook of the science of science communication (pp. 35-49). Oxford University Press.

Kakutani, M. (2018). The death of truth: Notes on falsehood in the age of Trump. Tim Duggan Books.

Kempthorne, J. C., \& Terrizzi, J. A., Jr. (2021). The behavioral immune system and conservatism as predictors of disease-avoidant attitudes during the COVID-19 pandemic. Personality and Individual Differences, 178, 110857.

Korownyk, C.S., Kolber, M., McCormack, J.P., Lam, V., Overbo, K., Cotton, C., Finley, C.R., Turgeon, R.D., Garrison, S., Lindblad, A.J., Banh, H.L., Campbell-Scherer, D.L., Vandermeer, B., \& Allan, G.M. (2014). Televised medical talk shows-What they recommend and the evidence to support their recommendations: A prospective observational study. The BMJ, 349, g7346.

Krause, N. M., Brossard, D., Scheufele, D. A., Xenos, M. A., \& Franke, K. (2019). Trends-Americans' Trust in Science and Scientists, Public Opinion Quarterly, 83(4), 817-836.

Leary, M. R., Diebels, K. J., Davisson, E. K., Jongman-Sereno, K. P., Isherwood, J. C., Raimi, K. T., Deffler, S. A., \& Hoyle, R. H. (2017). Cognitive and interpersonal features of intellectual humility. Personality and Social Psychology Bulletin, 43(6), 793-813.

Lee, J. J. (2021). Party polarization and trust in science: What about Democrats? Socius. Lee, N. (2021). Do policy makers listen to experts? Evidence from a national survey of local and state policy makers. American Political Science Review, 1-12. 
Leviston, Z., Leitch, A., Greenhill, M., Leonard, R., \& Walker, I. (2011). Australians' views of climate change. http://www.garnautreview.org.au/update-2011/commissionedwork/australians-view-of-climate-change.pdf

Lu Y. (2015). Is experiential-intuitive cognitive style more inclined to err on conjunction fallacy than analytical-rational cognitive style?. Frontiers in Psychology, 6, 85.

McPhetres, J., Bago, B., \& Pennycook, G. (2019, November 19). Science beliefs, political ideology, and cognitive sophistication. https://osf.io/ad9v7/

Nichols, T. (2017). The death of expertise: The campaign against established knowledge and why it matters. Oxford University Press.

Norris, P., Pacini, R., \& Epstein, S. (1998). The Rational-Experiential Inventory, short form [unpublished inventory]. University of Massachusetts at Amherst.

O’Brien, T. C., Palmer, R., \& Albarracin, D. (2021). Misplaced trust: When trust in science fosters belief in pseudoscience and the benefits of critical evaluation. Journal of Experimental Social Psychology, 96, 104184.

O’Connor, C., \& Weatherall, J.O. (2019). The misinformation age: How false beliefs spread. Yale University Press.

Pacini, R., \& Epstein, S. (1999). The relation of rational and experiential information processing styles to personality, basic beliefs, and the ratio-bias phenomenon. Personality and Individual Differences, 76, 972-987.

Pennycook, G., Fugelsang, J. A., \& Koehler, D. J. (2015). Everyday consequences of analytic thinking. Current Directions in Psychological Science, 24(6), 425-432.

Pennycook, G. \& Rand, D. G. (2021). The psychology of fake news. Trends in Cognitive Sciences, 25(5), 388-402. 
Pinker. S. (2021). Rationality: What is, why it seems scarce, why it matters. Viking.

Pornpitakpan, C. (2004). The persuasiveness of source credibility: A critical review of five decades' evidence. Journal of Applied Social Psychology, 34, 243-281.

Porter, T., \& Schumann, K. (2018). Intellectual humility and openness to the opposing view. Self and Identity, 17, 139-162.

Rekker, R. (2021). The nature and origins of political polarization over science. Public Understanding of Science, 30(4), 352-368.

Robert Wood Johnson Foundation. (2021, May). The public's perspective on the United States public health system. https://cdn1.sph.harvard.edu/wpcontent/uploads/sites/94/2021/05/RWJF-Harvard-Report_FINAL-051321.pdf

Rutledge, P. E. (2020). Trump, COVID-19, and the war on expertise. The American Review of Public Administration, 50(6-7), 505-511.

Shtulman, A. (2017). Scienceblind: Why our intuitive theories about the world are so often wrong. Basic Books.

Surowiecki, J. (2004). The wisdom of crowds: Why the many are smarter than the few and how collective wisdom shapes business, economies, societies and nations. Doubleday.

Swami, V., Voracek, M., Stieger, S., Tran, U. S., \& Furnham, A. (2014). Analytic thinking reduces belief in conspiracy theories. Cognition, 133(3), 572-585.

Swedroe, L.E., \& Berkin, A.L. (2020). The incredible shrinking alpha: How to be a successful investor without picking winners (2nd ed.). Harriman House.

Tetlock, P.E. (2005). Expert political judgment: How good is it? How can we know? Princeton University Press. 
Toplak, M. E., West, R. F., \& Stanovich, K. E. (2011). The Cognitive Reflection Test as a predictor of performance on heuristics-and-biases tasks. Memory \& Cognition, 39(7), 12751289.

Tranter, B. (2011) Political divisions over climate change and environmental issues in Australia. Environmental Politics, 20(1), 78-96.

Whitmarsh, L. (2011). Scepticism and uncertainty about climate change: Dimensions, determinants and change over time. Global Environmental Change, 21, 690-700.

Wikforss, Å. (2017). Alternativa fakta: Om kunskapen och dess fiender. Fri Tanke.

Wolf, M., Krause, J., Carney, P.A., Bogart, A., \& Kurvers, R. H. J. M. (2015) Collective intelligence meets medical decision-making: The collective outperforms the best radiologist. PLoS One 10(8), e0134269.

World Health Organization. (2020, September 23). Managing the COVID-19 infodemic: Promoting healthy behaviours and mitigating the harm from misinformation and disinformation. https://www.who.int/news/item/23-09-2020-managing-the-covid-19-infodemic-promotinghealthy-behaviours-and-mitigating-the-harm-from-misinformation-and-disinformation 
Table A1. Demographic characteristics of participants in Studies 1-3.

\begin{tabular}{|c|c|c|c|}
\hline & Study 1 & Study 2 & Study 3 \\
\hline $\mathrm{N}$ & 303 & 265 & 1431 \\
\hline Age (mean, SD) & $36.3(10.4)$ & $35.2(10.4)$ & $39.8(12.6)$ \\
\hline Gender $(\%$ female $)$ & $40.6 \%$ & $43.6 \%$ & $49.5 \%$ \\
\hline \multicolumn{4}{|l|}{ Ethnicity (\%) } \\
\hline American Indian or Alaskan Native & 1.0 & 0.4 & N/A \\
\hline Asian & 7.6 & 6.0 & 9.2 \\
\hline Black or African-American & 8.9 & 9.8 & 8.7 \\
\hline Hispanic & 3.6 & 5.3 & 6.9 \\
\hline White & 77.6 & 76.2 & 78.4 \\
\hline Other & 1.3 & 1.9 & 1.0 \\
\hline \multicolumn{4}{|l|}{ Education } \\
\hline Less than high school & 0.3 & 0.0 & 0.5 \\
\hline High school or equivalent & 14.9 & 12.8 & 11.2 \\
\hline Some college & 17.5 & 19.2 & 26.8 \\
\hline Vocational/associate degree & 15.2 & 12.1 & N/A \\
\hline 4-year degree & 40.6 & 45.7 & 43.3 \\
\hline Graduate degree & 11.6 & 10.2 & 18.0 \\
\hline Annual Income (median category) & $\$ 40-50,000$ & $\$ 50-60,000$ & $\$ 30-40,000$ \\
\hline
\end{tabular}

Note: In Study 3, demographic questions were changed so that multiple ethnicities could be selected (for a total percentage greater than 100); vocational/associate degree and American Indian or Alaskan Native were also removed as response options for Study 3. 